\title{
Screencasting Ethics and Values: Teaching Contemporary Legal Issues and Collective Legal Values through Live Screencasting
}

\author{
Words: 5,120 (Excluding bibliography)
}

\begin{abstract}
In the post-LETR environment, many questions still currently hang over the position of ethics and legal values in undergraduate legal education. The clear disjunction between the centrality of ethics in the profession and its absence from education was highlighted by the review as an area of proposed improvement. Furthermore, our students continually seek new mediums to engage with important legal subjects and issues, especially in the age of social media. With this in mind, Plymouth Law

School has begun to fill this lacuna through using contemporary video resources to encourage consideration of legal values. This article evaluates live screencasting of current affairs to incite critical reflection upon collective legal values.
\end{abstract}

\section{INTRODUCTION}

Through a consideration of the concerns raised by the Legal Education and Training review (LETR), this article proposes a simple, yet engaging method that involves students in current debates and value-based discussions in order to encourage a wider interaction with contemporary legal issues and collective legal values. This article will explain contemporary legal issues and provide a definition of collective legal values. Finally, it will provide an outline, analysis and reflection on using screencasting technology to engage first year law students in current affairs, while explaining how these can be used as a vehicle for teaching legal values and modern employability skills.

\section{CONTEXT: THE OUTCOME OF THE LETR FOR ETHICS AND VALUES}

The recommendations address those aspects of LSET that have been highlighted by the research as either currently deficient or in need of reconsideration to ensure the future effectiveness of the system. Chief amongst these are: knowledge and skills gaps in respect of legal values and professional ethics, communication, management skills and equality and diversity awareness ${ }^{1}$

Since the publication of the LETR, there has been an increased examination of the suitability of ethical and values-based education in law schools. One of the principal

\footnotetext{
${ }^{1} \mathrm{~J}$ Webb, J Ching, P Maharg and A Sherr, Setting Standards: The Future of Legal Services Education and Training Regulation in England and Wales (London: Legal Education and Training Review, 2013) (LETR Report). Available at: <http://letr.org.uk/the-report/index.html> at xii
} 
disjunctions highlighted by the report was the importance of professional ethics and values in legal practice, but its noticeable absence in undergraduate legal education. The report specified that:

The centrality of professional ethics and legal values to practice across the regulated workforce is one of the clearest conclusions to be drawn from the LETR research data, and yet the treatment of professional conduct, ethics and 'professionalism' is of variable quality across the regulated professions. There was general support in the research data for all authorised persons receiving some education in legal values and regulators are encouraged to consider developing a broad approach to this subject rather than a limited focus on conduct rules or principles. ${ }^{2}$

Whilst this finding has inevitably encouraged a more substantial discussion about the role of ethics in undergraduate education, ${ }^{3}$ the English and Welsh jurisdiction has always lacked dedication to exploring values, rights and ethics in the academic stage of training. ${ }^{4}$ This is largely due to the prevalent black letter tradition of law schools ${ }^{5}$ and the tendency for modern legal training to be compartmentalised rather than viewed holistically. The black letter tradition still overshadows the contemporary legal academy, just as it did when Sugarman highlighted this in 1991.6 This substantive conservatism has been diluted slightly by post-modernist approaches to legal study and attempts to examine the role of the law in context. However the foundations of legal knowledge, set by the professions, still dictate and forward this devotion to the black letter curriculum.

Furthermore, the rigid adherence to the academic, vocational and practical stages of legal training has stagnated the development of each of these individual areas, as each focuses on maintaining their own traditions and positions within this educational structure. Although the legal profession outlines the core curriculum in each of these stages and each phase of education has a distinct focus on an aspect professional practice, there is little overlap between the stages. The substantive study of law remains the domain of the academic stage, whereas professional ethics and responsibilities exist in the sphere of vocational training. Yet this model is distinctly

\footnotetext{
2 ibid, xiii

${ }^{3}$ See L Webley, 'Legal Ethics in the Academic Curriculum: 'Correspondent's Report from' the United Kingdom' (2011) 14(1) Legal Ethics, 132-134 and PB Wachs, 'Teaching Legal Ethics: Exploring the Continuum' (1995) 58 (3) Law and Contemporary Problems, 153-172

${ }^{4}$ For example, see R Brownsword, 'Ethics and Legal Education: Ticks, Crosses, and Question-Marks,' (1987) 50(4) The Modern Law Review, 529-535, C Menkel-Meadow "Can a law teacher avoid teaching legal ethics?" (1991) 41 Journal of Legal Education, 3, K Economides, 'Anglo-American Conceptions of Professional Responsibility and the Reform of Japanese Legal Education: Creating A Virtuous Circle?' (2007) 41 (2) The Law Teacher, 155, K Economides and J Webb, "Do Law Schools Care About Law Students and Legal Values?" (2000) 3 (1) Legal Ethics, 1-9,

${ }^{5}$ AC Hutchinson, "Beyond Black-Letterism: Ethics in Law and Legal Education." (1999) 33(3) The Law Teacher, 301-309

${ }^{6}$ D Sugarman, 'A Hatred of Disorder: Legal Science, Liberalism and Imperialism' in P Fitzpatrick, ed. Dangerous Supplements. Resistance and Renewal in Jurisprudence (London: Pluto, 1991), 34
} 
flawed and, since the LETR, a more holistic approach to legal education needs to be considered. This process should begin with a more substantial integration of legal values, ethics and legal skills. This is something that Plymouth University has instigated in earnest. The optimal approach to assimilation is something that has been widely considered.

For a number of years, the suitability of professional ethical education in the undergraduate law program has been deliberated, but has generally been the purview of the postgraduate vocational courses (LPC and BPTC). This paper does not seek to argue that professional ethics, the professional codes of conduct and concepts of professionalism should be taught in undergraduate law programmes, but instead considers how the lack of education around values could be addressed in light of the findings and recommendations of the LETR. The professional codes of conduct should remain the focus of the vocational stage, but more should be done to address important legal values during the academic stage.

Recommendation 7 of the LETR directly addresses how this should be achieved in the future of legal education. The report explains how "the learning outcomes at initial stages of LSET should include reference (as appropriate to the individual practitioner's role) to an understanding of the relationship between morality and law, the values underpinning the legal system, and the role of lawyers in relation to those values." ${ }^{7}$ It is clear that the LETR did not intend to position the codes of conduct or issues around professional conduct in the initial stages of legal education, but instead it aims to give students a more general appreciation of the law and lawyers role in society, alongside core values for fair legal administration.

The author's conception of collective legal values are closely linked to professional ethics and the aims of professional codes of conduct, but deal more substantially with wider jurisprudential issues that exist in the effective administration of justice within society. Concepts such as access to justice, neutral partisanship, equality, and fairness in legal proceedings are all important collective legal values, but they can also include issues around the suitability of our present adversarial system or how far our present system serves all individuals within society. ${ }^{8}$ However, while "the ethics of the legal profession are intimately linked to wider social values but are adapted to recognise the special role that lawyers play in society," ${ }^{9}$ these collective legal values are jurisprudential concepts that are of vital importance, not just for the legal

\footnotetext{
${ }^{7}$ LETR Report, xiv

${ }^{8} \mathrm{C}$ Menkel-Meadow, 'Forward Telling Stories in School: Using Case Studies and Stories to Teach Legal Ethics' (2000) 69 Fordham Law Review, 816

${ }^{9} \mathrm{~A}$ Boon and J Levin, The Ethics and Conduct of Lawyers in England and Wales, (Oxford: Hart Publishing, 2000), 6
} 
profession, but for the good of society. These collective legal values can, and should, be infused throughout legal study. ${ }^{10}$

The author argues that this notion of collective legal values should be used to educate all law students in the wider jurisprudential concepts, more substantially than has been done previously, regardless of their future progression into legal practice. These fundamental ideas are vitally important to legal education at the academic stage. While professional ethics and professional codes of conduct are important areas of study for potential lawyers, the education of collective legal values is more important for students at the degree stage, due to the various post-graduate employability routes.

While there is a clear intersection between professional ethics and these collective legal values, both need to be considered as separate spheres of study. Boon and Levin have described this juncture:

It is clear that the particular concept of justice pursued by lawyers is the defence of rights of individual citizens against a powerful enemy, the state. On this view, the lawyers role in society, the good the profession promotes, is access by citizens to vigorous representation within closely circumscribed rules provided by a court which is independent of the state. ${ }^{11}$

It is the author's argument that in order to conform to the existing educational paradigm, the teaching of professional ethics should be confined to the vocational stage of academic training, namely the LPC and the BPTC, and that the academic stage should be a foregrounding in collective legal values. This would benefit all students and encourage a more profound approach to the ethical components of the professional qualification.

With the current threats facing the traditional model of legal services and the everdeclining reputation of lawyers (often exacerbated by their representation in popular culture), it is becoming ever more important that there is an adherence to core legal values in order to improve public perception and legitimise the professions role in society. As Boon and Levin highlighted:

But the continuing legitimacy of a profession's social role derives from the nature of the good, which it secures for citizens and on its effectiveness on securing that good. Health is the good pursued by the medical profession and, it is usually asserted, justice is the good pursued by the legal profession. ${ }^{12}$

\footnotetext{
10 See generally, DL Rhode, 'Ethics by the Pervasive Method' (1992) 42(1) Journal of Legal Education, 31-56 and C Menkel-Meadow and RH Sander, 'The Infusion Method at UCLA: Teaching Ethics Pervasively' (1995) 58(3) Law and Contemporary Problems, 129-138

11 ibid, 27 A Boon and J Levin, The Ethics and Conduct of Lawyers in England and Wales, (Oxford: Hart Publishing, 2000), 27

12 ibid, 22
} 
A substantial redesign of ethical education across the legal curriculum must be of paramount importance in order to ensure that graduates are focused on the good pursued by the profession, and continue this process of legitimisation. ${ }^{13}$

There are numerous ways in which this could be achieved. For example, Mitchell Travis (University of Exeter) engages students in ethical and professional discussions based around popular culture and society's view of the lawyer. ${ }^{14}$ This course allows the student to interrogate the representation of the lawyer in popular culture as a "barometer" of public opinion, acting as a starting point for more detailed discussions about lawyer's regulation and their social obligations to justice. This course demonstrates an innovative, yet deeply profound approach to ethical education, drawing upon an important area of legal study to encourage critical thought around the lawyer's position in society.

In Plymouth Law School, the author has redeveloped one of the compulsory LLB modules to address the deficiencies highlighted in recommendation 7 of the LETR. This module, Contemporary Legal Issues, encourages students to consider the wider role of the law and the lawyer in society and allows the student to interrogate their own moral and social understandings of these in relation to current affairs. This article will now explain further how these issues have been addressed through the redevelopment of 'Contemporary Legal Issues' to question our 'collective legal values' and how the author has exploited an innovative mode of delivery to encourage critical thought around these ethical, value-based subjects.

\section{DEFINING 'CONTEMPORARY LEGAL ISSUES' AND THEIR RELATIONSHIP TO 'COLLECTIVE LEGAL VALUES'}

Contemporary Legal Issues $(C L I)^{15}$ is a twenty credit compulsory module for all first year students enrolled on the LLB Law programme. ${ }^{16}$ This module is taught over both teaching terms and is generally delivered in a weekly, two-hour large group interactive lecture. The interactivity of these sessions can been varied, and past sessions have incorporated debates, in-class polls, field trips and film screenings. ${ }^{17}$ During the first few weeks of term, students usually find these different modes of delivery challenging, with active participation and engagement inevitably limited. This is largely due to the usual issues around the transition from previous study or

\footnotetext{
${ }^{13}$ DL Rhode, 'Ethics by the Pervasive Method' (1992) 42(1) Journal of Legal Education, 55

${ }^{14} \mathrm{M}$ Travis, Teaching Professional Ethics through Popular Culture (2015) Forthcoming

${ }^{15}$ LAW1204 - Contemporary Legal Issues

${ }^{16}$ Candida Harris, a former colleague at Plymouth Law School, originally established this course. I have merely adapted it and refocused its aims and objectives to reflect the recommendations made by the LETR. I am forever indebted to her for her advice and assistance in establishing such a forward thinking module, and her continued support during the process of transition.

${ }^{17}$ The aim of this varied format was to also appeal to as many different learning styles as possible, and therefore engage as many individual students as possible.
} 
employment to university life, as well as the different approach to study taken by this course when compared to the delivery of other modules. However, as the course progresses participation, engagement and interaction increases. The importance of encouraging debate and discussion is of paramount importance in developing critical and analytical thinking, while also 'teasing-out' considerations of legal values.

The overall aim of this module is to develop critical thinking and critical awareness about the role of law in dealing with the challenges of social change in the $21^{\text {st }}$ century, with particular reference to conflicts arising from socio-economic change, globalism and environmental pressures. Furthermore, this module aims to consider wider collective legal values related to the role of law and lawyers in society. These discussions are always led by a current news story or ongoing social debate. For example, the class discussed the legal, social, moral and ethical issues around the reemployment of Chedwyn Evans post-conviction, and explored the governments proposed changes to anti-terror legislation through the lens of human rights. This naturally led to discussions around legal issues, ethical issues and an analysis of the role of law and lawyers in society. They explored themes such as access to justice, neutral partisanship, the importance of independent courts and judiciary, the virtues and pitfalls of professional self-regulation, equality and diversity, and the universality of rights, freedoms and liberties. These discussions enable students to consider the universal values around legal administration and consider the disjunction between moral and legal values within society. CLI also specifically explores the role of lawyers and the law within society, examining the disjunction between the ideal of the lawyer as a guardian of justice or as a fomenter of strife. Students benefit from the experience of being taught by numerous guest lecturers who discussed legal and ethical issues based upon their research interests. This exposes the students to more varied subject matter and wider contentious issues, while also allowing students to engage more directly with research-led teaching. Students are encouraged to think more substantially about the law in context of these specialisms and the key ethical debates within them.

Contemporary Legal Issues purposely considers the relationship between law and current affairs, in order to illustrate to students the pervasive nature of law in society and the far-reaching consequences of social issue on the law. While this encourages a wider consideration of legal values and supports academic and professional development, it also has a key goal for improving employability. Students are encouraged to critical reflect directly on the legal issues of contemporary affairs and consider the role of law in addressing social concerns. Due to the ever-increasing focus by employers on commercial awareness and contextual influences on professional practice, we must encourage a substantial approach to developing this critical thinking and contextual skill-set, otherwise we are inappropriately preparing our students for the legal marketplace. CLI seeks to develop these critical analytical skills and encourages students to consider the social, commercial and legal implications of current affairs. 
Finally, this course also provides students with the opportunity to reflect upon their own social engagement and digital professional networking. Social media and professional networking are a distinct reality of the student experience in the twentyfirst century. Regardless of whether lecturers and law schools use social media tools to engage with students, most students use such tools as their window to the world. However, few students really consider the consequences of their online actions, or truly understand how these tools can be used for their own personal development. CLI has encouraged students to reconsider their online presence and has stimulated reflection upon the strategic usage of social media for networking purposes. This course has also encouraged students to consider tools such as twitter and flipboard as a way to remain abreast of contemporary legal issues and current affairs. This has been an important aspect of the course, and has advocated, from the outset of their legal studies, continued engagements with legal developments.

This module is assessed in two parts. The first is a reflective study log (which is worth thirty percent of the total mark) and the second is a research essay (the remaining seventy percent). The aim of the study log is for students to keep a running record or diary of the work done on the module. The purpose for this is to encourage students to critically reflect upon contemporary issues alongside their own working practises, to organise their study schedule and activities, and to provide evidence of the in-depth research undertaken for the module. There is no set format for the study log but it has been specified in recent years that it must be wordprocessed. However, in future years the students will also be given the opportunity to submit a collection of reflective videos or audio podcasts to compliment the differing modes of delivery within the course. Furthermore, the renewed approach to assessment will develop student's oral argument skills and improve their ability to orally reflect upon their skills development. ${ }^{18}$ Finally, the opportunity of video assessment will allow students to perform a greater level of synthesis ${ }^{19}$ of argument and research, ${ }^{20}$ which can then be converted into a greater level of critical analysis in the second assessment component through a more complete, holistically consideration of the course.

The second assessment component is a research essay and draws directly on the debates and discussion undertaken in the large group sessions, encouraging

\footnotetext{
${ }^{18}$ See generally, MNK Boulos, I Maramba and S Wheeler, 'Wikis, blogs and podcasts: a new generation of Web-based tools for virtual collaborative clinical practice and education' (2006) 6 (1) BMC Medical Education, 41-49 who outline the importance of 'mind-tools' to encourage cognitive reflection through a deeper engagement with learning materials. This is particularly true when students are asked to reflect upon their practice orally and repackage their reflection in oral presentation.

${ }^{19}$ Synthesis as defined in BS Bloom (ed.) Taxonomy of Educational Objectives, the classification of educational goals - Handbook I: Cognitive Domain, $2^{\text {nd }}$ ed. (New York: Longman, 1984), 162-185

${ }^{20}$ The ability to orally reflect upon wider issues allows the student to synthesise more holistically. See also, within a medical context, S Atkins and K Murphy, 'Reflection: a Review of the Literature' (1993) 18(8) Journal of Advanced Nursing, 1188-1192
} 
students to critical analyse a number of contemporary legal issues. The major focus of the essay component is to write an argument that critically evaluates legal and ethical issues, with particular reference to UK law, raised by the one of the titles. These essay titles are also written to encourage a focus on collective legal values, something that will be defined in the next section. The students are told clearly in the assessment brief that there is no 'right answer' to any of the titles. They are encouraged to take a narrow point of view or discuss the pertinent issues more widely. While most of the titles are very broad, they are informed that they do not have to cover everything; instead they must focus on developing a coherent reasoned argument. The basis of the essay is a research project, so students are expected to have significant legal content, while considering legal problems and issues related to their chosen title. This must be supported with good quality sources including primary legal sources such as statutes and/or case law where appropriate. The proposed essay titles focus on both domestic and international issues, and students are expected to determine their focus. For example, where a title requires discussion of domestic law, the primary focus should be on the UK. Although students are informed that a comparative approach is acceptable, and some of the titles relate to international law, in which case their approach should be much wider. This opportunity to complete a research project facilitates a more in-depth connection with themes and subjects discussed in lectures, and provides students the chance to explore these collective legal values more substantially.

One innovative and engaging method through which students are engaged with contemporary legal issues, their ethical implications and accompanying value-based discussions is live screencasting. This article will now explore how screencasting provides an engaging tool for encouraging thought and discussion on these pervasive legal values.

\section{SCREENCASTING ETHICS AND VALUES}

Screencasting is simply a digital recording of your computer screen, which is accompanied by audio narration or a 'talking-head' webcam video clarifying the displayed content. ${ }^{21}$ There are numerous software applications that facilitate this including Monosnap. ${ }^{22}$ Screencasts are occasionally used as instructional videos in other disciplines ${ }^{23}$ and are also commonly found online as tutorials for various different spheres including computing, video games and editing. ${ }^{24}$ The author has

\footnotetext{
${ }^{21} \mathrm{~S}$ Winterbottom, 'Virtual Lecturing: Delivering Lectures using Screencasting and Podcasting Technology' (2007) 18 Planet, 6

${ }_{22}$ Monosnap <https://monosnap.com/welcome> accessed 1 June 2015

${ }^{23}$ L Mathew, 'Creating Screencasts' (2014) 32 CIN: Computers, Informatics, Nursing, 465-470 and K Kwon, D Saparova and K Hoffman, 'Online lecture capturing system: Expected and actual effects of implementation in a problem-based learning medical curriculum' (2014) Medical Teacher, 1-7

${ }_{24}$ Many screencast tutorials can be found on video sharing websites (such as YouTube and Vimeo) and deal with all manner of subject matter. The author is particularly interested in video editing and
} 
also used screencasting to create tutorials for online collaboration tools in the legal curriculum..$^{25}$ The significance of recordings such as these are that they go beyond mere video or audio podcasts discussing relevant issues, but allows the creator to demonstrate or explore content on screen (in real time). This enables the students to examine the resource with direct guidance, observe every click-through, and then replicate this experience themselves. ${ }^{26}$ This means that students can see what the lecturer sees, watch what the lecturer watches, and read what the lecturer reads. ${ }^{27}$ This also allows the student to interact more extensively with sources that would be traditionally linked via a static $\mathrm{html}$ web link in a VLE, ${ }^{28}$ thus providing an innovative and contemporaneous mode of engagement ${ }^{29}$ that goes beyond the existing paradigm of fixed text resources. ${ }^{30}$

While screencasting has generally been used to deliver lecture content ${ }^{31}$ (especially where lecture capture software such as Echo 360 are unavailable), it is the authors contention that screencasting can be deployed more effectively to address current skill gaps and explore contentious legal issues. A particular application of screencasting for legal studies can be to assist and encourage the analysis of legal sources, other documents or articles. One skill that many students struggle to develop early in their legal studies is the ability to satisfactorily read, examine and assimilate case judgements, while also critiquing academic scholarship to formulate independent opinions on legal issues. Furthermore, students often find it difficult to critically reflect upon online resources (including the ability to examine the reliability of sources) and relate these to legal and ethical issues. Screencasting allows the lecturer to directly instruct the students on the required approaches needed to critically explore these sources, using visual instruction and tasks can be set around the student undertaking their own investigation following the example set by the lecturer.

production, and much of what the author has learned has been through online screencast tutorials. These were the initial impetus for the adoption of this technology in exploring online resources and contemporary news sources.

${ }^{25}$ The author has created screencast tutorials for accessing and using a Virtual Board Room (using the SANSspace platform) for file management and online collaboration, and has screencast tutorials on using webcams for recording video assessment.

${ }^{26}$ For use an innovative use in chemistry to explore worked examples, see generally KJ Crippen and BL Earl, 'Considering the Efficacy of Web-Based Worked Examples in Introductory Chemistry' (2004) 23(2) Journal of Computers in Mathematics and Science Teaching, 151-167

27 ibid

${ }^{28}$ VLE - Virtual Learning Environment

${ }^{29}$ S Brittain, P Glowacki, J Van Ittersum and L Johnson, 'Podcasting Lectures: Formative Evaluation Strategies Helped Identify a Solution to a Learning Dilemma' (2006) 29(3) Educause Quarterly, 31

${ }^{30}$ See generally, JL Hill and A Nelson, 'New Technology, New Pedagogy? Employing Video Podcasts in Learning and Teaching about Exotic Ecosystems' (2011) 17(3) Environmental Education Research, 393-408

${ }^{31}$ Op cit n.21 
Screencasting has also been used as a form of assessment. ${ }^{32}$ This places screencasting in the hands of the student and individuals are expected to explain the content of their presentation for their peers and the lecturer. While examples of this include students describing mathematical explanations, ${ }^{33}$ this could also be used to assess engagement and understanding of legal sources or legal issues. This has a clear advantage when used in conjunction with a VLE. Each student (or student group) contribution can be added to an online wiki to create a repository of sources that can be used as a reference tool for future use. This article will now explore how screencasting has been used to explore ethics and values in contemporary legal issues and assist students in the development of their critical and analytical faculties.

In 2000, Menkel-Meadow explained how stories and narrative forms could be utilised to teach ethics and values, ${ }^{34}$ by giving "us a closer, more intimate, as well as broader experience (even if only vicariously) of situations - others, so we might function better in our own." ${ }^{35}$ Numerous scholars since have argued the same, specifically using popular culture to explore ethics ${ }^{36}$ and using film to explore law within its sociolegal context. ${ }^{37}$ Contemporary legal issues uses a similar conceptual basis to explore collective legal values, using news stories and current events to provide a narrative for exploring these notions, a tangible anchor point for exploring the far-reaching consequences of laws role in society. ${ }^{38}$ These current affairs

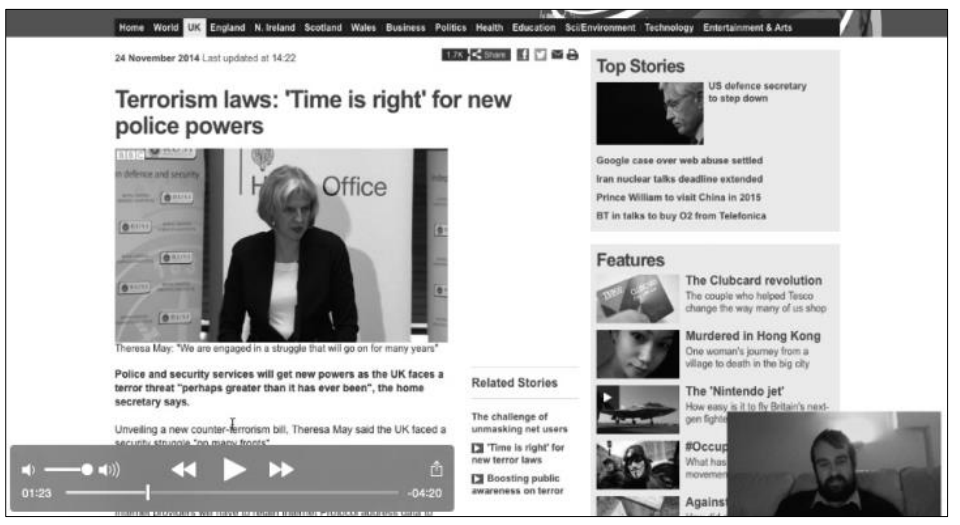
highlight the contemporary nature of the subject and require students to explore collective legal values in relation to events occurring in contemporary society.

While the aim of the course is to encourage independent thought and critical analysis, screencasting has been used to introduce students to pertinent stories and demonstrate how news stories can be examined for their pertinent legal, ethical and

\footnotetext{
${ }^{32}$ T Croft, F Duah and B Loch, 'I'm worried about the correctness': undergraduate students as producers of screencasts of mathematical explanations for their peers - lecturer and student perceptions' (2013) 44 International Journal of Mathematical Education in Science and Technology, 1045-1055

33 ibid

34 Op cit, n.8

35 ibid, 792

36 ibid

${ }^{37} \mathrm{C}$ Ashford, 'Law, Film and the Student Experience' (2005) 4 Web Journal of Current Legal Issues and B Green, 'Less is More: Teaching Legal Ethics in Context' (1996-1997) 39 William \& Mary Law Review 357

${ }^{38}$ See DL Rhode, 'Ethics by the Pervasive Method' (1992) 42(1) Journal of Legal Education, $42-43$
} 
moral issues. This has been done as a preparatory task in advance of a large group session and as a consolidation task to reflect upon the material considered. Initially, the lecturer is able to direct the students to sources and can draw attention to resources that may be missed by students undertaking their own research. This is particularly important in the twenty-first century, as sources have become more diverse. ${ }^{39}$ Needless to say, student are warned as to the veracity of such sources but are also encouraged to go beyond the traditional news services to broaden their critical perspectives. The value of screencasting is that students can be introduced to the news story and the lecturer can explain his or her thought-process and focus upon key pertinent points, in order to highlight the ethical or moral arguments within the story. The lecturer is then able to explain his or her own viewpoints and encourage students to develop their own arguments around the subject matter. These screencasts can also be valuable in highlighting more general jurisprudential concepts that will not be the obvious legal subject matter of the case. Herein is the

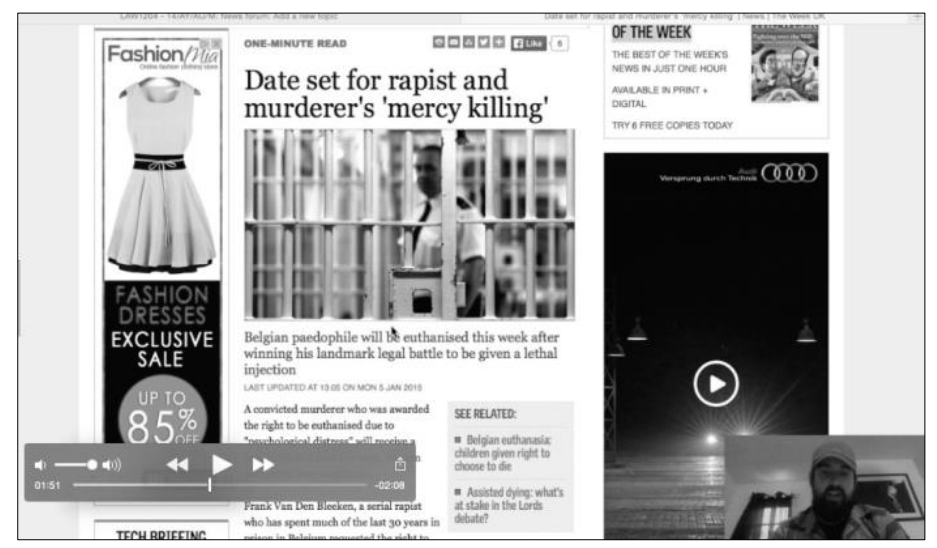
principal reason for using these sources, the ability to place collective legal issues into context. By demonstrating the influence that law and legal values have on society, the paramount importance of such values can be explained and rationalised to achieve a greater understanding of how the law

functions for the benefit of the wider community.

Upon reflection, the students have been very receptive to these resources. During the interim module evaluation, a number of students have requested a more extensive usage of screencasts and more opportunity to participate in accompanying debates. Students appreciate the lecturers perspective as it teaches them to properly read sources for the pertinent issues and wider legal values. Furthermore, it is clear from the student's individual study logs that many students have engaged more substantially with current affairs and digital sources, and have clearly grasped a consideration of wider ethical issues and legal values. In this respect, the screencasts are acting as an engaging tool for conveying an important legal subject matter.

However, one major setback of screencasting is that it creates a unilateral dialogue between lecturer and student, the lecturer essentially instructing the students. It is clear that this is a merely updated, technology-enhanced didactic approach. This has

\footnotetext{
${ }^{39}$ This can include online reports and commentary from legal professionals, online legal blogs and open-access research.
} 
been criticised by Resnick who claimed, "In most places where new technologies are being used in education today, the technologies are used simply to reinforce outmoded approaches to learning." 40 This is an accepted criticism of using new technological, and does demonstrate an ongoing issue with using digital tools to enhance established curriculum. Yet, this drawback can be addressed by incorporating debate forums and chat functions alongside these screencasts on the VLE. This blended approach ${ }^{41}$ to learning can facilitate a well-rounded appreciation of important legal subjects and appeal to a broader demographic of learning styles.

In the coming academic year, it is envisaged that there will be further developments in using screencasting technology to maintain engagement with these sources. These will also be complimented by specific research tasks and more-extensive debate and polling sessions. The overall goal is to take forward these resources and make them more interactive, in order to develop a more blended paradigm for considering legal values and examining contemporary legal issues. A further idea is to adapt the existing study log component of assessment, effectively replacing it with a screencast created by a student group. The student groups will be timetabled a week throughout both terms to select, research and present a current news story and its corresponding legal values story. They will be given guidance on using screencasting software to deliver their thoughts and research findings via a live screencast, and upload it to a DLE-hosted wiki. This would create a repository of materials for current and future course participants to consider various different opinions and issues, while also allowing the students to contribute to a community source.

\section{CONCLUSION}

Contemporary Legal Issues has provided a vehicle for reflection on collective legal values and ethical issues, while screencasting has been used as a means through which to anchor these values in real-world narratives. As was recommended by LETR, there is a clear deficiency in the focus on widespread legal values in undergraduate legal education, something that must be addressed. The disjunction between the esteem given to ethics and values in professional practice and its deficiency in the academic stage of training, is something that requires immediate attention. In no way should the undergraduate law degree become an ethical training ground for lawyers, instead, it should be a place to develop legal values and ethical understandings that would be beneficial to society, regardless of the students future career. Issues such as access to justice, the suitability of legal processes, and the

\footnotetext{
${ }^{40} \mathrm{M}$ Resnick, 'Rethinking Learning in the Digital Age' in GS Kirkman et al, The Global Information Technology Report 2001-2002 (Oxford: OUP, 2002), 32 -

<http://hasp.axesnet.com/contenido/documentos/harvard\%20global\%20it\%20readiness.pdf\#page=48 $>$ accessed 21 Jan 2015

41 JISC, 'Introduction to e-Learning,' jiscgigitalmedia.ac.uk

<http://www.jiscdigitalmedia.ac.uk/guide/introduction-to-elearning > accessed 28 July 2014
} 
role of the lawyer in society should be considered more than the preserve of practising lawyers, but instead should be of paramount importance to anyone who undertakes a legal education. However, these deeper jurisprudential issues need to be given a real-world focus, something that the students can engage with, relate to and feel a part of. The law is inherently pervasive. It is a social discipline that touches upon all manner of contemporary issues and ethical dilemmas. By providing these real stories through which to interrogate legal values, students are given a window onto the world and the role that law and lawyers play in maintaining the social good. Screencasting can act as a virtual window, where students are challenged, reassured and enlightened by the world around them, and inspired by their potential future.

\section{BIBLIOGRAPHY}

Ashford, C, 'Law, Film and the Student Experience' (2005) 4 Web Journal of Current Legal Issues

Atkins, S, and Murphy, K, 'Reflection: a Review of the Literature' (1993) 18(8) Journal of Advanced Nursing, 1188-1192

Bloom, BS (ed.) Taxonomy of Educational Objectives, the classification of educational goals - Handbook I: Cognitive Domain, $2^{\text {nd }}$ ed. (New York: Longman, 1984)

Boon, A, and Levin, J, The Ethics and Conduct of Lawyers in England and Wales, (Oxford: Hart Publishing, 2000)

Boulos, MNK, Maramba, I, and Wheeler, S, 'Wikis, blogs and podcasts: a new generation of Web-based tools for virtual collaborative clinical practice and education.' (2006) 6 (1) BMC Medical Education, 41-49

Brittain, S, Glowacki, P, Van Ittersum, J, and Johnson, L, 'Podcasting Lectures:

Formative Evaluation Strategies Helped Identify a Solution to a Learning Dilemma' (2006) 29(3) Educause Quarterly, 24-31

Brownsword, R, 'Ethics and Legal Education: Ticks, Crosses, and Question-Marks,' (1987) 50(4) The Modern Law Review, 529-535

Crippen, KJ, and Earl, BL, 'Considering the Efficacy of Web-Based Worked Examples in Introductory Chemistry' (2004) 23(2) Journal of Computers in Mathematics and Science Teaching, 151-167 
Croft, T, Duah, F, and Loch, B, 'I'm worried about the correctness': undergraduate students as producers of screencasts of mathematical explanations for their peers - lecturer and student perceptions' (2013) 44 International Journal of Mathematical Education in Science and Technology, 1045-1055

Economides, K, 'Anglo-American Conceptions of Professional Responsibility and the Reform of Japanese Legal Education: Creating A Virtuous Circle?' (2007) 41(2) The Law Teacher, 155-168

Economides, K, and Webb, J, "Do Law Schools Care About Law Students and Legal Values?" (2000) 3(1) Legal Ethics, 1-9

Green, B, 'Less is More: Teaching Legal Ethics in Context' (1996-1997) 39 William \& Mary Law Review, 357-392

Hill, JL, and Nelson, A, 'New Technology, New Pedagogy? Employing Video Podcasts in Learning and Teaching about Exotic Ecosystems' (2011) 17(3) Environmental Education Research, 393-408

Hutchinson, A, C, "Beyond Black-Letterism: Ethics in Law and Legal Education." (1999) 33(3) The Law Teacher, 301-309

JISC, 'Introduction to e-Learning,' jiscgigitalmedia.ac.uk $<$ http://www.jiscdigitalmedia.ac.uk/guide/introduction-to-elearning > accessed 28 July 2014

Kwon, K, Saparova, D, and Hoffman, K, 'Online lecture capturing system: Expected and actual effects of implementation in a problem-based learning medical curriculum' (2014) Medical Teacher, 1-7

Mathew, L, 'Creating Screencasts' (2014) 32 CIN: Computers, Informatics, Nursing, 465-470

Menkel-Meadow, C, 'Can a law teacher avoid teaching legal ethics?' (1991) 41 Journal of Legal Education, 3-10

Menkel-Meadow, C, and Sander, RH, 'The Infusion Method at UCLA: Teaching Ethics Pervasively' (1995) 58(3) Law and Contemporary Problems, 129-138

Menkel-Meadow, C, 'Forward Telling Stories in School: Using Case Studies and Stories to Teach Legal Ethics' (2000) 69 Fordham Law Review, 787-816

Monosnap <https://monosnap.com/welcome> accessed 1 June 2015 
Resnick, M, 'Rethinking Learning in the Digital Age' in Kirkman, G, S, et al, The Global Information Technology Report 2001-2002 (Oxford: OUP, 2002) p. 32 $<$ http://hasp.axesnet.com/contenido/documentos/harvard\%20global\%20it\%20r eadiness.pdf\#page $=48>$ accessed 21 Jan 2015

Rhode, DL, 'Ethics by the Pervasive Method' (1992) 42(1) Journal of Legal Education, 31-56

Sugarman, D, 'A Hatred of Disorder: Legal Science, Liberalism and Imperialism' in Fitzpatrick, P, ed. Dangerous Supplements. Resistance and Renewal in Jurisprudence (London: Pluto, 1991), 34-67

Travis, M, Teaching Professional Ethics through Popular Culture (2015) Forthcoming

Wachs, P, B, 'Teaching Legal Ethics: Exploring the Continuum' (1995) 58(3) Law and Contemporary Problems, 153-172

Webb, J, Ching, J, Maharg, P, and Sherr, A, Setting Standards: The Future of Legal Services Education and Training Regulation in England and Wales (London: Legal Education and Training Review, 2013) Available at: $<$ http://letr.org.uk/the-report/index.html> accessed 21 Jan 2015

Webley, L, 'Legal Ethics in the Academic Curriculum: 'Correspondent's Report from' the United Kingdom' (2011) 14(1) Legal Ethics, 132-134

Winterbottom, S, 'Virtual Lecturing: Delivering Lectures using Screencasting and Podcasting Technology' (2007) 18 Planet, 6-8 